\title{
Fraternal Twin
}

National Cancer Institute

\section{Source}

National Cancer Institute. Fraternal Twin. NCI Thesaurus. Code C73428.

Either of the two offspring from separately fertilized ova during the same pregnancy. 